\title{
O bebê e a construção de significações, em relações afetivas e contextos culturais diversos
}

\author{
Katia de Souza Amorim \\ Carolina Alexandre Costa \\ Luciana Aparecida Rodrigues \\ Gabriella Garcia Moura \\ Ludmilla Dell'Isola Pelegrini de Melo Ferreira \\ Universidade de São Paulo - Ribeirão Preto, SP, Brasil
}

\begin{abstract}
Resumo
A perspectiva histórico-cultural considera a capacidade de significação como condição especificamente humana. Nesta pesquisa, investigaram-se processos de significação em bebês, em suas relações afetivas e vínculos. Conduziram-se estudos de casos múltiplos, exploratórios, longitudinais, em contextos diversos (casa, creche, abrigo). A análise desdobra-se de videogravações e entrevistas, com foco no comportamento de choro/incômodo. Verificou-se que significações e práticas dirigidas aos bebês variavam (busca insistente pelo sorriso; atenção e cuidado; consolo à distância). Em função dos vínculos/contextos, significações eram vivenciadas através da intercorporeidade bebê-parceiros, estes últimos sendo tanto adultos, como pares de idade. No drama das relações, concretizavam-se significados sobre a posição do bebê naquele espaço, papel a ser assumido e o esperado da criança, exigindo recursos diferenciados da mesma. A direção da construção de significados dependeu de contexto/interação. Significando e sendo significada pela emoção e corporeidade, na relação bebê-ambiente, a criança constrói significações enraizadas na cultura, constitutivas da sua subjetividade. Novos estudos são requeridos. Questões são levantadas para debate no cuidado infantil.
\end{abstract}

Palavras-chave: Bebê, Significação, Contexto, Vínculo, Afetividade.

\section{The infant and his/her meaning construction within diverse affective relations and cultural contexts}

\begin{abstract}
Cultural-historical perspective considers signification processes as a specifically human condition. Thus, signification processes were investigated through infants' affective relations and bonds. Exploratory multiple case studies were conducted, longitudinally, within diverse contexts (home, daycare center and foster institution). Analysis unfolded from videotapes and interviews, focused on infants' crying/annoying behavior. It was verified that significations and practices varied largely (searching for a smile; attention and care; distant comforting). Depending on bonds, significations were experienced through infant-partner intercorporeality, partners being either adults or peers. Within relational drama, significations were materialized regarding infant's position, his/her role and expectations, requiring differentiated means. The direction of the signification construction depended on contexts/interactions. Attributing meanings and being signified through emotion and embodiment, throughout infant-environment relation, the child constructs significations rooted on culture, which are constitutive of their subjectivities. New studies are required. Issues are raised regarding infant care.
\end{abstract}

Keywords: Infant, Signification, Context, Attachment, Affection.

Endereço para correspondência: Katia de Souza Amorim. Rua C., 20, Quinta da Boa Vista B. Ribeirão Preto/SP, Brasil. CEP: 14031-796. E-mail: katiamorim@ffclrp.usp.br. Telefone: +55 163602 3850. Fax: +55 163636 4992.

Agradecimentos à FAPESP, CNPq e FFCLRP - USP. Ainda, às famílias, crianças e instituições que se disponibilizaram a participar das pesquisas. 


\section{El bebé y la construcción de significaciones en relaciones afectivas y contextos culturales diversos}

\section{Resumen}

En la perspectiva histórico-cultural, se considera la capacidad de significación como condición específicamente humana. Así, se han investigado procesos de significación en bebés en sus relaciones afectivas y vínculos. Se han conducido estudios de casos múltiplos, exploratorios, longitudinales, en diversos contextos (casa, guardería, abrigo). El análisis que se presenta es producto de videos y entrevistas, con enfoque en el lloro/molestia. Se ha verificado que las significaciones y las prácticas dirigidas al bebé variaban, como búsqueda insistente por la sonrisa; atención y cuidado; consuelo a distancia. En función de los vínculos/contextos, las significaciones eran vivenciadas por la intercorporeidad de bebés-compañeros, estos siendo tanto adultos como compañeros por edad. En el drama de las relaciones, se concretizaban significados sobre la posición del bebé en aquél espacio, papel a ser asumido o lo que era esperado por el niño, exigiendo recursos diferenciados. La dirección de la construcción de significados dependió del contexto/interacción. Con la relación bebé-ambiente, que se constituye través la emoción y corporeidad, se han construido significaciones enraizadas en la cultura, constitutivas de su subjetividad. Nuevos estudios permitirán profundizar la comprensión de esos mecanismos. Cuestiones son propuestas para una discusión de las implicaciones de estos resultados a la atención a los bebés.

Palabras clave: Bebé, Significación, Contexto, Vínculo, Afectividad.

Investigações sobre desenvolvimento nos primeiros anos de vida têm sido historicamente realizadas, porém, como os autores partem de diferentes perspectivas (psicanalítica, etológica, sistêmico-dinâmica, psicobiológica, teoria da atividade, sócio-histórica, etc.), inúmeras proposições têm sido elaboradas, cada qual sendo ponto de ancoragem para formas diversas de conceber a criança, investigá-la e atuar junto a ela.

Dentre os diversos aspectos discutidos relativos ao desenvolvimento do bebê, destacase o papel do vínculo afetivo. Nessa temática, Carvalho (2005) afirma que, historicamente, verifica-se extensa variabilidade de formas de organizações familiares e sociais, a família refletindo as estruturas sociopolíticas e econômicas das sociedades, resultando em diversas práticas e modos de cuidados de crianças. Segundo ela, a despeito desses diferentes modos de organizações e relações, em comum, há o papel do vínculo afetivo, o qual representa componente de sociabilidade humana, presente enquanto estrutura na espécie. Contudo, o significado do vínculo afetivo e de seu papel varia de acordo com as perspectivas teóricas, como em Wallon (1959), Bowlby (1969), dentre outros.

Bowlby (1969), por um lado, elaborou a teoria do apego, fazendo-a em diálogo com a psicanálise, contrapondo-se à ideia de que o vínculo se desenvolveria de modo secundário à satisfação das necessidades fisiológicas. Com base também na etologia, ele propôs que o ser humano nasce com sistemas de comportamentos prontos a serem ativados dentre eles, o sistema do apego. Este teria evoluído na filogenia, garantindo a sobrevivência da espécie, pois ele seria um sistema que asseguraria o cuidado e a proteção do jovem, por promover proximidade da criança em relação ao cuidador, com quem construiria uma ligação durável. Especificamente, o cuidador é considerado como devendo ser uma figura sensível e responsiva aos comportamentos do bebê e, dentre os cuidadores, deu-se destaque ao adulto, particularmente à mãe como figura central de apego.

Para Bowlby (1969), o apego é visto como fundamental. Assim, segundo ele, caso a relação de apego não seja adequadamente estabelecida, pode resultar em transtornos no desenvolvimento afetivo e social da criança. Nessa perspectiva, ele refere ser necessário minimizar, particularmente na relação com a criança pequena, a ocorrência de afastamentos. Ele afirma, ainda, haver predição de riscos de falha no desenvolvimento, no caso de bebês cuidados por longo período em ambiente 
institucional, com pouca consistência de interação com uma figura de apego.

Já Wallon (1959), ao elaborar sua teoria psicogenética, apoiando-se em uma perspectiva evolucionista darwiniana articulada a uma abordagem materialista-histórica, trata diferenciadamente da questão. Por um lado, Wallon (1979) entende, como Bowlby, que o bebê humano passa por um período de imperícia prolongada, em que o outro social é condição fundamental à sobrevivência da criança. Porém, o que promoveria a ligação não seria a existência de sistemas que impeliriam a criança em busca de proximidade. Para Wallon, a necessária sociabilidade dependeria da solidariedade de comportamentos e atitudes entre o bebê e as pessoas do entorno. E aquela solidariedade de comportamentos seria possibilitada inicialmente por um aparelho expressivo (emoção) que teria força contagiosa, a qual propaga expressividade de um indivíduo a outro, assegurando a comunidade necessária das reações. Para Wallon, as emoções estão na base da filogênese e fornecem o primeiro e mais forte vínculo entre os seres da espécie.

Essas manifestações afetivo-comunicativas na sincronização das relações do bebê com o adulto se dão, como discutem Carvalho (1998) e Fogel (1993), em função de que o bebê nasce equipado com um repertório biológico de grande complexidade e alto grau de organização sensório-motora, perceptual e expressiva. Meltzoff e Brooks (2007), ao discutirem a comunhão do bebê com o outro, afirmam que mesmo o recém-nascido tem reações de satisfação diante do rosto humano, igualando expressões faciais exibidas por outras pessoas. Já Trevarthen (2005) verificou o reconhecimento e a preferência pela voz humana, com alternações vocais do tipo diálogo; e, em torno de dois meses, vocalizações simultâneas e no mesmo tom. Observou, ainda, sincronia interacional com coordenação da movimentação geral do corpo em ritmo com a fala que ouvem. Ribeiro e Bussab (1998) referem ecos, espelhos e danças biológicas, favorecedores de percepção compartilhada, sincronizações interacionais e contágio emocional.

Para algumas vertentes teóricas, nessa perspectiva de solidariedade e comunhão de comportamentos, o destaque é dado ao papel do adulto. Através do vínculo afetivo que se constrói, o adulto não só garante a sobrevivência da criança, como se comunica com ela e intermedeia as relações do bebê com o mundo. Imerso num universo simbólico, o adulto apresenta o mundo ao bebê e lhe atribui significações, através do uso de instrumentos culturais, dentre os quais a linguagem. Entendese ainda que, através de seu corpo, expressividade, gesto e disposições afetivas, o bebê participa ativamente desses processos (Amorim \& Rossetti-Ferreira, 2008).

No entanto, Galvão (2001), baseada em perspectiva walloniana, afirma que o gesto pode exprimir disposições afetivas. Todavia, a autora pontua que, embora constitua etapa de acesso à atividade simbólica, a emoção não se confunde com ela, não sendo vista como linguagem. Tal posicionamento se contrapõe ao anterior e deixa em suspenso a questão de como, nas relações afetivas em construção, o bebê apreende e participa da cultura. Isso leva à questão da relação do bebê com a linguagem.

\section{Linguagem, comunicação e significação nos primeiros anos de vida}

As temáticas da comunicação e aquisição da linguagem não são novas, perpassando obras de filósofos e pesquisadores da Psicologia e Linguística. Elas se relacionam a diferentes facetas do desenvolvimento e, em função de perguntas específicas e pressupostos de base, o tema é explorado a partir de abordagens diversas e, até mesmo, contraditórias (Piaget \& Inhelder, 1978; Wallon, 1979; Bruner, 1983; Vygotsky, 1991; Pinker, 2002). Quando os autores se debruçam sobre material empírico, aborda-se a questão a partir de aspectos como a expressão emocional, além da imitação, comunicação e significação. Porém, predominantemente, os autores não tratam dos processos de comunicação no primeiro ano de vida como sendo da ordem da linguagem. Àquele processo, os autores se referem à protoconversação (Reddy \& Trevarthen, 2004), aos precursores da linguagem, à comunicação pré-verbal (Meltzoff \& Brooks, 2007) ou prélinguística (Mendes \& Seidl Moura, 2004).

Apesar desses posicionamentos, de maneira geral, os diversos autores destacam o papel da linguagem na constituição da criança. Assim, Lemos (1986), numa abordagem sóciohistórico-construtivista, afirma que a linguagem (verbal) representa ação sobre o outro (comunicativa) e sobre o mundo (cognitiva), a linguagem alterando o universo da criança e sendo alterada por ele. A linguagem não seria 
reflexo do funcionamento psíquico, mas condição do próprio funcionamento. E para Smolka (1995), com base em uma abordagem histórico-cultural, a linguagem (verbal) não é só meio e modo de (inter/oper)ação, mas é produto histórico; é constitutiva/constituidora do sujeito (da e na linguagem).

Entretanto, a despeito de um enfoque dominante da linguagem como ligado ao aspecto verbal, outros posicionamentos se apresentam. Por exemplo, ao tratar do processo comunicativo do/no/com o bebê, Schirmer, Fontoura e Nunes (2004) afirmam que, antes de a criança começar a falar, ela está habilitada a usar o olhar, a expressão facial e o gesto. E, para Mendes e Seidl Moura (2009), o bebê começa a perceber e a antecipar comportamentos emocionais do outro e a atribuir-lhes significados.

Santana, Guarinello, Berberian e Massi (2008), mais ainda, tecem críticas à discussão da expressividade e dos gestos em separado da língua. Para os autores, a linguagem é prenhe de gestos, que variam da especificação mínima da ordem do simbólico, ao uso efetivo dessa ordem. Para eles, desde criança, é-se sujeito do gesto e é através de seu uso, nas interações, que se adquire saber sobre os usos de uma língua.

Enfrentando, portanto, um campo pleno de contradições, Rodríguez (2006) argumenta ser mais produtivo falar em mediação semiótica, dando relevância a outros signos usados pelo bebê. De forma semelhante, Correia (2009) caminha no sentido de deslocar a questão do signo (verbal), destacando a necessidade de se trabalhar com a noção de significação e de processo de construção de significados.

Uma análise geral da produção da área evidencia, assim, que correntes históricoculturais ou sócio-históricas destacam o papel do vínculo afetivo do bebê com o outro na constituição da criança. $\mathrm{O}$ vínculo seria, por um lado, promovido pela afetividade e emoção que contagia e coloca as pessoas em comunhão. Através desta, dar-se-ia a mediação à criança, atribuindo-lhe e apreendendo significações. Apesar de se ter, nessas abordagens, elementos conceituais que se aproximam, verifica-se uma diversidade e complexidade nas formas de considerar a temática da linguagem, emoção, expressividade, comunicação e significação nos primeiros anos de vida. Mostra-se, então, relevante que se pontue a partir de que referencial e de que questões o presente trabalho parte.

\section{Vínculo, linguagem e significação numa perspectiva histórico-cultural}

$\mathrm{Na}$ abordagem histórico-cultural, de base deste estudo, a constituição do sujeito é pensada como se dando intrinsecamente articulada ao outro social, imerso na cultura, na/pela linguagem. Tal proposição é frisada, já que, apesar das inúmeras competências, o bebê humano é incapaz de sobreviver sozinho. Nesse sentido, Wallon (1959, citado por Werebe \& Nadel-Brulfert, 1986) afirma que a incompletude do bebê leva à necessidade íntima do outro, da sua assistência constante. É o outro que completa o bebê, compensa-o e o interpreta para o mundo e o mundo para ele. É através do outro que as atitudes do bebê tomam forma. Como ele afirma, o bebê humano é geneticamente social.

No entanto, segundo Pino (2000), Vygotsky afirma que, além da espécie humana, outras espécies também são dotadas de sociabilidade. O diferencial no humano estaria na cultura, através da qual o social adquire novas formas de existência. A sociabilidade biológica, sob a ação criadora do ser humano, transforma-se em diferentes modos de organização das relações. Ou seja, a sociabilidade humana não seria simplesmente dada pela natureza, mas assumida pelo ser humano que procura formas de concretizá-la.

Bussab, Pedrosa e Carvalho (2007), a partir de abordagem psicoetológica, também afirmam que o neonato é um ser biologicamente organizado para a vida sociocultural. De acordo com Ribeiro e Bussab (1998), o homem seria, a um só tempo, criatura e criador, a hominização implicando na aptidão natural para a cultura e a aptidão cultural para a natureza. Segundo eles, excelente evidência da evolução de comportamentos culturais é observada através da própria linguagem.

Em relação a esta última, Vygotsky (1991) foi um autor que desenvolveu extensas elaborações teóricas, destacando o papel do signo no processo de desenvolvimento. Ele afirma que, através da interação com outros sociais, a criança internaliza signos, os quais atuam como instrumento de mediação psicológica. A internalização do signo faz com que ele tenha função específica de ação reversa, conferindo formas qualitativamente novas à operação psicológica, permitindo ao indivíduo controlar seu próprio comportamento. O signo 
seria o próprio meio/modo de articulação das funções, acontecendo graças à linguagem.

Baseada naquele autor, Smolka (2004) especifica propriedades do signo (particularmente, o signo verbal). Segundo ela, o signo é reversível: significa tanto para quem o recebe quanto para quem o emite. O signo opera no campo da consciência, no qual ser autor e espectador constituem atributos de uma mesma pessoa. O signo atua como elemento mediador, operador e conversor das relações sociais em funções mentais. O signo age, repercute, reverbera como aquilo que se produziu e se estabilizou na história das relações interpessoais.

Intrinsecamente ligado ao signo, Vygotsky destaca o papel da significação. E, com base nesse autor, Smolka (2004) afirma que a significação faz parte da atividade humana, é concebida como produção material, de natureza social, de signos e sentidos, sendo produzida a partir de condições materiais de existência. A significação resulta, portanto, de relações sociais internalizadas. Porém, a autora frisa que o que é internalizado não são as relações materiais, mas a significação que elas têm para as pessoas. $\mathrm{O}$ que é internalizado é a significação que uma pessoa tem para as outras; o que o outro da relação tem para seu eu; o que, na dialética da relação, dá ao seu eu as coordenadas para saber quem é ele, que posição social ocupa e o que se espera dele. A significação representaria, assim, a atividade mais geral e fundamental do ser humano.

Nesse sentido, dentre outros, autores como Correia (2009) e Bruner (1983) colocam em destaque e reivindicam o estudo do processo de construção de significados. Especificamente para Correia, a linguagem poderia ser compreendida, dialeticamente, como produto e produtora da capacidade humana de construir significados. No entanto, para ela, a compreensão desse processo não seria solucionada pela sua tradução em linguagem devendo ser considerados outros componentes participantes do processo. Dentre estes, haveria a dimensão interacional - participação direta ou indireta de um Outro. Desta forma, a direção que a construção de significados pode assumir depende da interação com um Outro. A construção de significados existe a partir do Outro e, ao mesmo tempo, para o Outro.

Haveria, ainda, uma dimensão cultural, pois necessita de um sistema simbólico e de artefatos que possuam um significado compartilhado ou que possa ser compartilhado. $\mathrm{E}$, uma dimensão individual, porque a ação precisa ser dirigida e, geralmente, ser voluntária. Todos estes componentes estariam em um processo contínuo de mudança para produção de significados e ação. Dessa maneira, para a autora, o processo de construção de significados é que faz da linguagem uma atividade, uma construção dinâmica. Como ela afirma, ainda que haja um paralelismo, um interjogo, não há uma justaposição entre estes fenômenos.

E foi considerando que o ser humano é um ser da linguagem, como discutem os autores acima, e que ao ser humano é impossível não significar, como afirma Smolka (2004), que se interrogou como pensar os processos ligados ao bebê. Dado o relevo atribuído à significação e ao processo de construção de significados no desenvolvimento do ser humano, interrogou-se se este deveria/poderia ser considerado no caso de bebês, mesmo que estes ainda não tenham adquirido a linguagem verbal.

Tal questão se coloca, já que diferentes estudos empíricos (Fogel, 1993; Amorim, 2002; Vallotton, 2011, dentre outros) têm afirmado que o comportamento dos bebês se faz de maneira culturalmente adequada, em acordo com as significações do grupo social. Especificamente Amorim (2002), ao estudar adaptação de bebês à creche, verificou que eles modificavam o comportamento de acordo com diferentes práticas dos adultos (familiares e educadoras). Mesmo bebês bem novos, ao ingressarem na creche, agiam de acordo com as novas regras, mantendo formas construídas anteriormente com a família, ao mesmo tempo em que negociavam diferentes (rel)ações com os novos interlocutores. O que se concluiu é que, de alguma maneira, o bebê apreendia significações e as expressava nas relações.

Desta maneira, junto a outros autores, Amorim (2002) interrogou como, nas relações, os bebês lidam com as situações e se posicionam de acordo com as diferentes significações? Como o bebê apreende e expressa, age e se relaciona de acordo com as significações do grupo social? Ou, conforme interroga Fogel (1993), como bebês, em seus primeiros anos de vida, tornam-se participantes da cultura? Ainda, como pergunta ele, se o bebê não obtém informação pelas palavras, que tipo de informação ele está apreendendo e como está apreendendo? 
Coloca-se em questão, portanto, buscar compreender o processo de construção de significados no bebê. Como afirma Smolka (2004), vale indagar sobre a possibilidade de produção de sentidos, sobre condições de emergência e modos de elaboração, funcionamento e sustentação da significação.

Assim, considerando-se: 1) o papel central do estabelecimento de vínculos, fomentados também pelas manifestações emocionais; 2) que, a partir dos vínculos e relações afetivas, os parceiros sociais mediam, interpetam e atribuem significações junto ao bebê; e, 3) que ao ser humano é impossível não significar, a significação fazendo parte da atividade humana, representando não apenas uma capacidade intrinsecamente humana, mas condição daquilo que é especificamente humano (Smolka, 2004), traçou-se o objetivo de investigar processos de construção de significados em bebês, considerando-se as relações afetivas da criança, em diferentes contextos culturais.

\section{Método}

Baseadas em perspectiva históricocultural, entende-se que as significações construídas em relações e vínculos específicos devam ser analisadas contemplando-se o contexto. Em concordância com Bruner (1983), entendemos que estudos de desenvolvimento devam ser conduzidos na desordem da vida em casa em detrimento do artificial vídeolaboratório. Tal posicionamento também é defendido por Mendes e Seidl Moura (2009), que afirmam ser necessário ir ao ambiente natural para se investigar a microgênese $\mathrm{e}$ ontogênese.

Esta é a perspectiva do nosso grupo de pesquisa, não se restringindo, porém, à casa. Estudos vêm sendo conduzidos tanto em ambientes domésticos, como em instituição de acolhimento (abrigo) e de educação coletiva (creche). A meta é apreender, em diferentes contextos, elementos circunscritores dos processos, com suas potencialidades e limites (Rossetti-Ferreira, Amorim, Silva \& Carvalho, 2004). O ponto de partida é que, dada a história da humanidade (com toda sua (a)d(i)versidade de condições) e considerada a plasticidade cerebral humana, não se entende como plausível que o percurso de desenvolvimento se dê através de único caminho (criança "normal"), em condições específicas (bebê com a mãe, em casa). Deste modo, a meta é estudar processos em contextos diversos, não para comparação dos mesmos (e identificação do que falta, quando comparado à casa), mas de modo a se apreender indícios de recursos, percursos e potencialidades do desenvolvimento. Para isso, têm sido conduzidos estudos de caso.

\section{Os estudos de caso}

O estudo de caso (Yin, 2005) representa estratégia de investigação em função do tipo de questão de pesquisa - como determinado evento ocorre. No caso, se e como ocorrem processos de significação no bebê, em relações afetivas específicas, em contextos diversos.

O estudo de caso é usado, ainda, para o estudo de processos em que se busca preservar a complexidade e as características dos eventos dentro de contextos e relações. Em função disso, como Góes (1991) propõe, no estudo da construção de significados, deve se considerar a história, o tempo particular, o lugar de geração do enunciado e os envolvimentos intersubjetivos de dado discurso, configurando diferentes dimensões a serem analisadas.

Finalmente, a estratégia de estudo de caso é utilizada por se entender que se parte de hipótese de que bebês, antes da aquisição da linguagem verbal, já significam, questão que trava diálogo tenso com a literatura. A pesquisa impõe, assim, realização de estudos exploratórios, marca dessa estratégia de pesquisa.

Nesse sentido, estudos de caso múltiplos têm sido conduzidos, todos tendo sido aprovados pelo Comitê de Ética em Pesquisa CEP. A condução é norteada por preceitos da Resolução 196/96 do CNS, a participação das crianças sendo feita com consentimento das famílias, inclusive para a apresentação das imagens.

Dentre as pesquisas, vários são os trabalhos que vêm investigando vínculo, emoção, linguagem e significação de bebês no ambiente doméstico. Em cada pesquisa, foram feitas videogravações das (inter)ações do bebê, semanal ou quinzenalmente, variando o acompanhamento de três meses a um ano. Desses estudos, serão aqui apresentados dados de Marina, que foi acompanhada por um ano, desde o seu nascimento (Rodrigues, 2011; Ferreira, 2012).

Em relação aos bebês em creche, vários também são os trabalhos conduzidos. Episódios 
e questões a serem apresentadas se farão a partir dos estudos de caso de Amorim (2002) e Costa (2008, 2012). Os dois primeiros envolvem uma investigação longitudinal (semanal), por seis meses, de bebês em uma creche universitária. $\mathrm{O}$ terceiro envolve acompanhamento semanal, por quatro meses, de bebês que frequentaram uma creche hospitalar.

Finalmente, o estudo das relações afetivas e dos processos de significação de bebês em instituição de acolhimento vem sendo feito por Moura (2011), que acompanhou, semanalmente, por três meses, crianças pequenas frequentando um abrigo.

\section{Construção do corpus e análise dos dados}

Videogravações foram realizadas, guiadas para apreender expressões, reações e interações da criança com os familiares, outras crianças e/ou educadoras/funcionárias; ainda, a apresentação/mediação do ambiente, objetos e pessoas aos bebês. As gravações foram feitas com câmera móvel e durou, em média, uma hora diária.

A transcrição das cenas foi feita individualmente por criança selecionada. A transcrição foi registrada no programa Excel. Neste, tabularam-se, cronologicamente, todos os aparecimentos da criança, descrevendo-se a minutagem, o tempo e as pessoas presentes; ainda, se a criança manipulava objeto; e, quais eram as ações da(s) criança(s) e do(s) adulto(s), além de expressões faciais/corporais, olhares e falas/balbucios/vocalizações dos sujeitos. A tabulação descreveu, ainda, a concomitância dos eventos e sua sequência.

Dada a diversidade de situações encontradas, definiu-se aqui por um foco, destacando-se particularmente um eixo de expressividade emocional: o choro. Vale dizer que a noção de emoção utilizada neste trabalho se baseia na proposição de Wallon (1979), o qual considera as emoções como estando na base da filogênese, sendo um instrumento de sociabilidade. A emoção implica em contágio e solidariedade de comportamentos, sendo considerada para além da mímica facial, a expressividade também se dando através do corpo como um todo, além de vocalizações. Ainda nessa ótica, considerar a emoção implica abordar comportamentos que se identificam com a ação sobre o mundo exterior, pertencendo ao meio social, às relações, ao espaço em que se pode sentir seus efeitos. É, nesse sentido, desdobrando-se da proposição walloniana que, apesar das controvérsias, considera-se a emoção como um instrumento participante dos processos de construção de significados.

A partir da leitura do material, em contínua observação das videogravações, buscou-se apreender, nas peculiaridades comportamentais do bebê, nas situadas relações, elementos (manifestações emocionais e comunicativas) que pudessem ser sinalizadores de processos de significação. Parte do sistema sinalizador, a expressividade do bebê fornece pistas sobre atitudes com relação à própria criança e às outras pessoas; permite também focalizar aspectos intersubjetivos e dialógicos, destacando-se práticas sociais e suas condições. Como discutem Brannigan e Humphries (1972), através da expressividade, apreendem-se as circunstâncias em que os comportamentos ocorrem, pois é nessa configuração que o comportamento contém significado. Isso significou perguntar sobre as qualidades da ação, do gesto, da emoção, da relação com objetos e parceiros. Implicou ainda enfocar a significação nas negociações estabelecidas.

Em função da pergunta, tais aspectos orientaram a escolha dos episódios a serem analisados e levaram aos recortes que possibilitaram apreender indícios sobre significação em bebês, nas relações afetivas específicas, nos contextos especificados (casa, creche e abrigo).

\section{Resultados}

\section{Caso 1) Emoção e significação em bebê, na relação com familiares, em casa}

Para essa discussão, tomou-se uma cena recorrente dentre o conjunto de cenas deste bebê. Mas, antes, é importante dar alguns dados sobre o caso (Rodrigues, 2011). Especificamente, a mãe engravidou após vários anos de casada, sendo Marina uma filha desejada e planejada. A mãe trabalhou até o nascimento da filha, deixando o emprego alguns meses após o nascimento, para cuidar do bebê. Marina era a primeira filha do casal, mãecriança permanecendo juntas em casa. Além da mãe, a avó materna é bastante presente na casa e nas gravações. De modo geral, a relação com Marina é individualizada, a mãe referindo ter 
forte vínculo com a filha. $\mathrm{Na}$ cena discriminada, Marina está com três meses (Ferreira, 2012). À cena:

Marina está no quarto, sentada no bebê conforto, em cima da cama. Enquanto a mãe conversa com a pesquisadora, Marina se movimenta no bebê conforto, mexendo braços, pernas e emitindo alguns gemidos. A mãe se senta, então, ao lado do bebê, continuando a conversar com a pesquisadora. Marina passa a expressar alguns gemidos mais fortes; para, volta a gemer e enfim começa a chorar. A mãe a pega no colo, dizendo-lhe: "Que cara feia! Você tá querendo tomá banho? Deixa eu vê que deve estar cheia de cocô essa menina". Júlia (a mãe) deita Marina na cama, conversando com ela enquanto retira a fralda. Ao final, a mãe não coloca outra fralda, deixando o macacão aberto. Enquanto a mãe conversa com a pesquisadora, Marina volta a emitir alguns gemidos, a que a mãe diz "Tá com frio, Marina!? Tá com a mãozinha e os pezinhos gelados!". A mãe coloca, então, a fralda e embrulha a filha numa manta, falando que ela deve estar querendo mamar. Fica em pé com ela no colo, conversando com a pesquisadora. Marina continua a gemer, às vezes chorando, com expressão facial de irritação. A mãe vai até a sala, senta-se no sofá e começa a amamentar

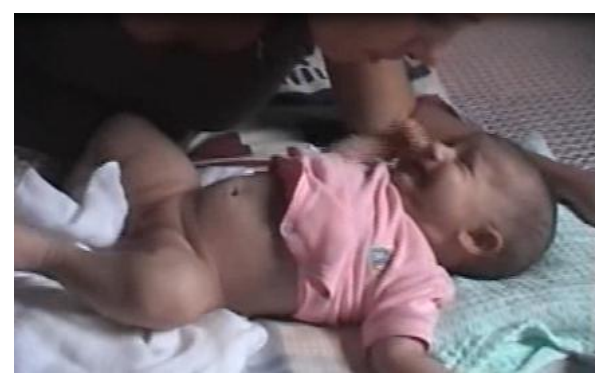

Figura 1

Como referido acima, esse tipo de sequência - em que mãe aborda a criança quando esta começa a resmungar ou a chorar mostra-se recorrente nas várias cenas, ao longo de todo o primeiro ano. Ainda, a partir das diferentes interpretações quanto ao motivo do choro, estratégias diversas são usadas, variando o tom das vocalizações, havendo mudanças de posição da criança, colocando-a face a face em relação ao adulto, mexendo em objetos e fazendo barulhos, dentre outros.
Marina, que ainda choraminga. $\mathrm{O}$ bebê começa a mamar, enquanto mãe, pesquisadora e avó conversam. Depois de quinze minutos, Marina para de mamar. O bebê fica passando o rosto na fralda, gemendo como se estivesse fazendo força. A mãe fala "É lá por baixo, é?!", enquanto dá batidas ritmadas, nas costas de Marina. Ela fica quieta, mas depois volta a se mexer, aparentemente tentando mudar de posição no colo da mãe. Depois de alguns gemidos, recomeça a chorar, com expressão de incômodo enquanto a mãe a vira, deitando a filha no colo novamente. Marina continua gemendo e a mãe pergunta se ela quer mamar mais, colocando-a no outro peito. Marina chora mais forte. A mãe vê que a filha estava com a perna dobrada. Ela arruma a perna da filha e dá o outro peito para ela mamar. Marina mama cerca de seis minutos e para, com expressão de cansaço, meio adormecida. A mãe coloca a filha em pé e ela arrota, deitando relaxada no colo da mãe, de olhos fechados. Marina abre os olhos e a mãe faz carinho com a boca na cabeça dela. Ela fica com os olhos entreabertos. Depois se vira, mudando de posição no colo e adormecendo.

As imagens abaixo explicitam a expressividade presente no episódio.

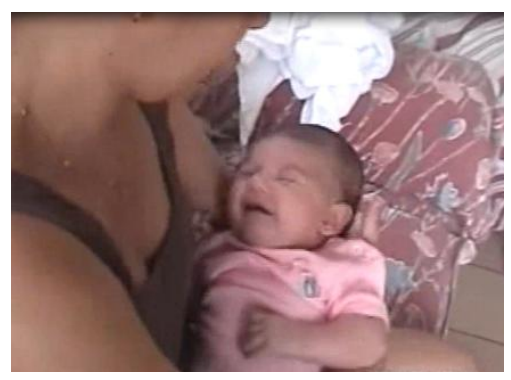

Figura 2

\section{Caso 2) Emoção e significação em bebês, em relação com familiares, educadoras e pares de idade, na creche}

Algumas situações a serem aqui apresentadas mostraram-se também recorrentes no cotidiano da creche. A primeira situação se baseia em estudo de Amorim (2002), que investigou adaptação de bebês à creche. $\mathrm{O}$ que se verificou é que grande preocupação das mães é de que seus filhos, ainda no primeiro ano de vida, por passarem quase oito horas 
diárias na creche, apeguem-se mais à educadora do que à mãe. $\mathrm{O}$ temor de um apego não direcionado exclusivamente à mãe faz com que muitas delas procurem ser o centro da atenção da criança, mesmo no ambiente da creche. Faz, também, com que as educadoras se constranjam frente a esse sentimento, chegando a verbalizar "Não se preocupe, que o filho é teu!" (educadora Mirtes).

Além disso, nesse contexto, a razão adulto-criança é bastante diferenciada do ambiente doméstico usual contemporâneo, havendo um adulto cuidando de várias crianças (no caso, uma educadora para seis bebês). Isso impõe limite e critérios de atenção e cuidados,

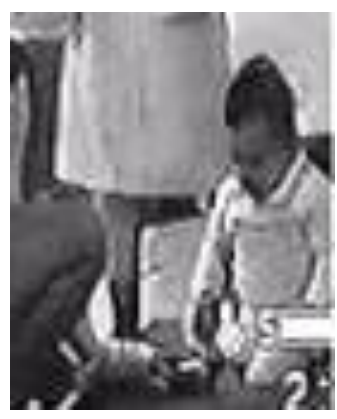

Figura 3

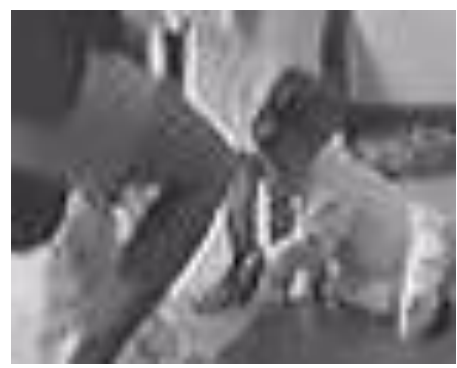

Figura 5

No primeiro caso (Costa, 2008), Isa (11 meses) tem um objeto tomado pelo irmão Armando (11 meses) (figura 03). Isso faz com que Isa chore e o faz dirigindo seu olhar à mãe, que está em pé, ao seu lado (figura 4). Porém, a mãe está conversando com a educadora, não a atendendo de imediato. Isa faz a seguir, então, dois movimentos com a mão em direção a Armando. Em um primeiro, ela estende a palma da mão aberta, com a palma virada para cima (figura 5). Ao movimento da irmã, Armando vira o corpo e afasta dela sua mão e objeto. Isa se coloca então em posição de engatinhar, apóia-se sobre a mão esquerda e estende sua como relata a educadora Zilda: "A gente corre atrás dos que tão chorando, dos que vêm nas tuas pernas toda hora. Tem hora que a gente precisa prestar atenção pra não deixar os que não choram de lado [Como ela diz] Quem não chora não mama!".

Frente à dinâmica de funcionamento da instituição, portanto, nem sempre o adulto conseguer atender à criança de maneira mais imediata. Nesse ambiente, o parceiro mais disponível é o par de idade. Nessas condições, o bebê deve lidar com uma série de situações e, ainda, encontrar recursos frente a incômodos e conflitos, buscando superá-los. Os dois casos abaixo explicitam a situação.

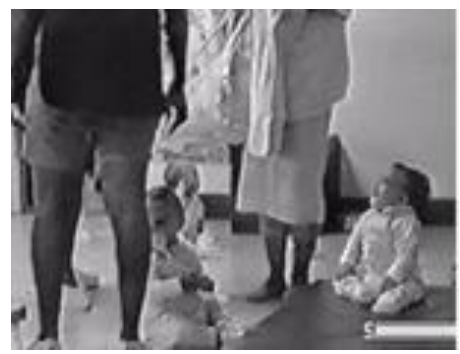

Figura 4

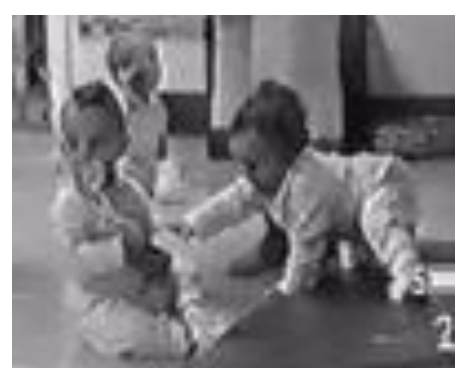

Figura 6

mão direita na direção de Armando. Agora, sua mão está com a palma virada para baixo e ela busca pegar e puxar o objeto da mão do irmão (figura 6). Ele afasta mais ainda o corpo. Isa volta a chorar, olhando novamente na direção da mãe.

Em outro episódio, acompanhou-se a interação de dois bebês de 11 meses, em que, novamente, há a perda de um objeto, o choro e a negociação (Costa, 2012). No caso, Priscila, que antes detinha um carrinho vermelho, perdeo para Vitória (figura 7). A posse é então disputada através da ação de puxar o carrinho e mantê-lo junto ao corpo, com a palma da mão 
sobre ele (figura 8). Frente ao choro de Priscila (figura 09), Vitória aponta o dedo na direção de onde estão outros carrinhos. Priscila

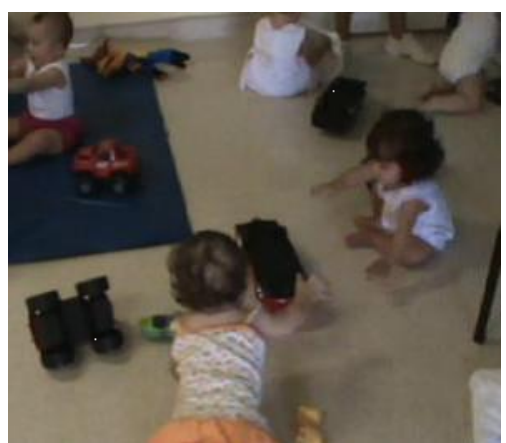

Figura 7

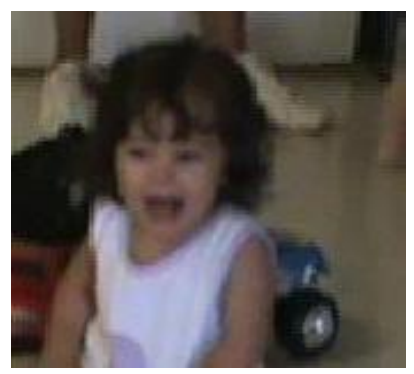

Figura 9 acompanha com o olhar a indicação de Vitória, volta a olhar para Priscila e sorri (figuras 10 e 11).

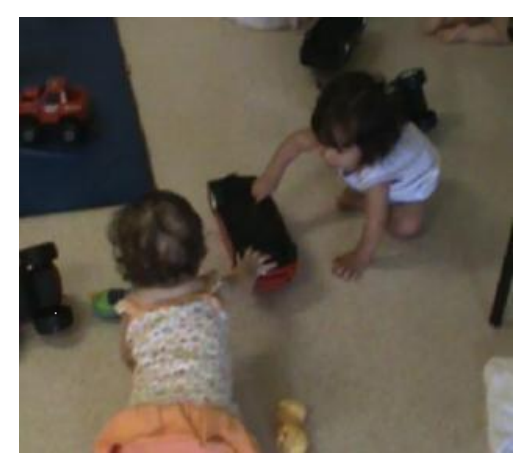

Figura 8

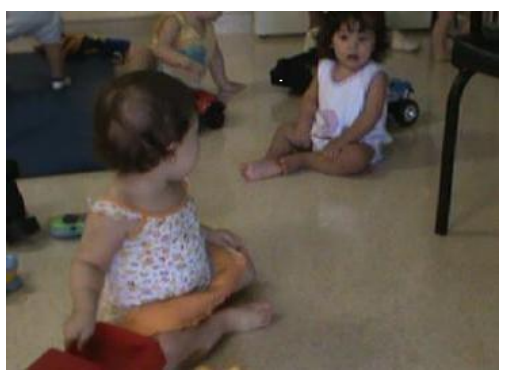

Figura 10

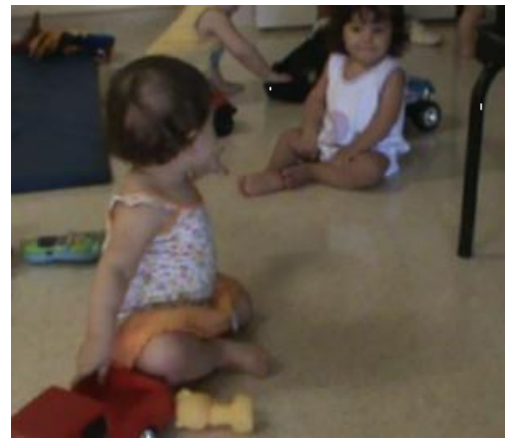

Figura 11

\section{Caso 3) Emoção e significação em bebê, em relação com funcionários e pares de idade, em uma instituição de acolhimento}

Ao longo da história, práticas de assistência às crianças e aos adolescentes alijados do convívio familiar de origem - por orfandade ou circunstâncias resultantes de más condições de vida - vêm sofrendo mudanças de concepções, políticas, funcionamento e denominações. Resultado de diferentes processos históricos e sociais, tais práticas passaram de uma dimensão espacial (com apoio a adoção) a uma dimensão relacional (com apoio à família de origem ou extensa). Culminou, assim, nos atuais programas de proteção integral, dentre eles, nos serviços de acolhimento institucional, embuídos de novas práticas de cuidados em relação a essas crianças (Moura, 2011). 
Verifica-se, contudo, que, apesar dessas novas proposições, não há ruptura com sentidos preexistentes, havendo sobreposição de práticas discursivas. Nessa superposição, marca no cuidado é a concepção de que é necessário que as funcionárias mantenham certo distanciamento das crianças. No estudo de Moura (2011), a coordenadora da instituição refere que a orientação dada às funcionárias é de que realizem o cuidado das crianças sem que estas se acostumem a ficar no colo. Como frisa,

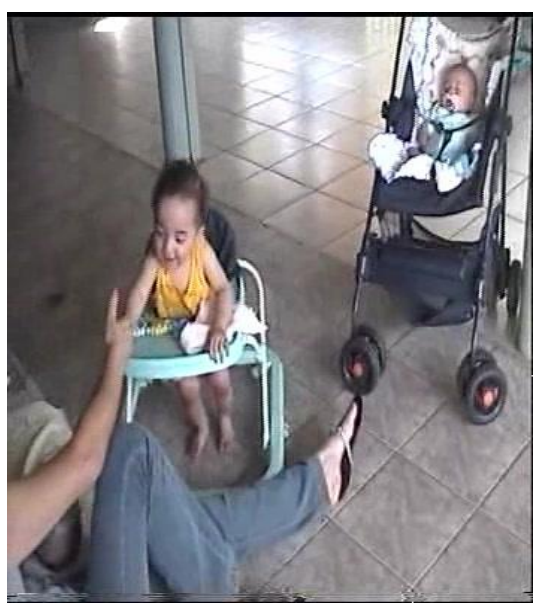

Figura 12

Nesse contexto, em que a razão adultocriança é baixa e em que os adultos não devem pegar a criança (para não se apegarem à criança e não deixarem a criança se apegar às funcionárias), verifica-se instensificação da relação entre pares, pares estes muitas vezes constituídos pelos próprios irmãos. Assim, em

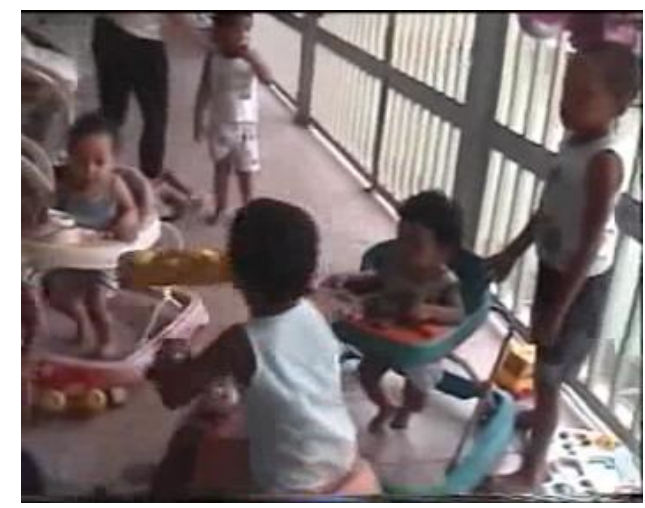

Figura 14 é importante para as crianças "não se acostumarem mal" e "não se apegarem" às funcionárias: quando a criança ou mesmo o bebê chora, deve-se deixá-lo "chorar um pouquinho". Se necessário, a ação da funcionária é de longe, cantando, falando alto, chamando a criança. No entretempo, a meta é deixar a criança em localização em que ela se distraia com o movimento do entorno, colocando o carrinho do bebê perto das pessoas ou em frente à televisão.

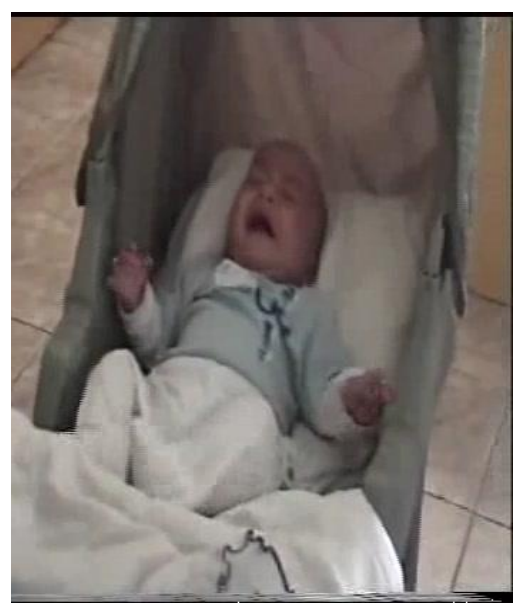

Figura 13

disputas e choro por parte das crianças pequenas, outras crianças participam, buscando soluções, como no caso abaixo, em que Jorge (o garoto de camiseta azul) pegou um objeto de Regina (a criança no andador branco) e Ramires (de camiseta branca) resgatou para devolvê-lo.

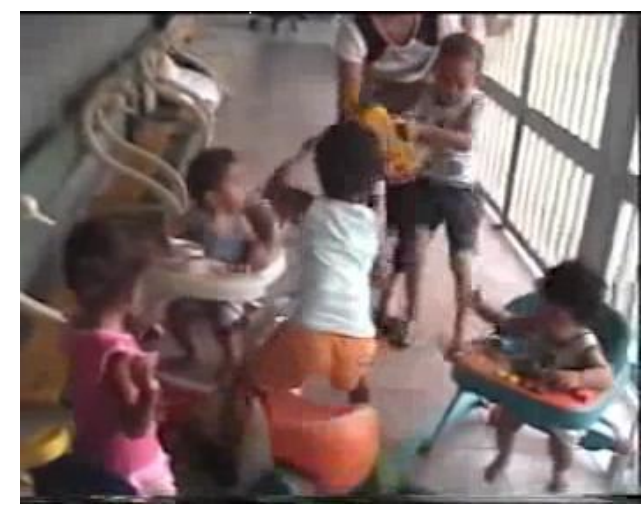

Figura 15 


\section{Discussão}

Compreende-se que, no contexto social contemporâneo, diferentes são os arranjos familiares e variados são os modos de cuidados do bebê, havendo diferenças mesmo no caso do cuidado realizado no ambiente doméstico. Apesar disso, análise geral do caso evidenciou que a situação se mostra em consonância com a literatura que aponta: o bebê tem lugar de destaque na família (particularmente dentro de famílias de camadas médias), acabando por reorganizar relações, em que a mãe para de trabalhar, de modo a garantir o cuidado direto da criança. Tal prática se ancora em concepções sociais que assinalam a cada um dos membros da família seus papéis e suas funções; e, que atribuem à mulher/mãe o papel de nutridora e educadora do filho, como discute Vaitsman (1994). Como referido na introdução, tais concepções apontam à mãe como central nos cuidados da criança pequena, sendo ela a figura principal de apego, para que a criança se desenvolva de modo social e afetivamente saudável (Bowlby, 1969).

E, ainda que no cotidiano da família ocorram situações em que a mãe não coloque o bebê como aspecto único e central de sua vida (como, no caso, no período em que a mãe ainda trabalhava fora de casa, após o nascimento da criança; ou, mesmo quando ela realiza atividades de arumação da casa), de maneira geral (e retratada no episódio, a partir do recorte do choro) a relação com o bebê se dá através de um grande número de interações dos familiares (mãe, pai e avó), interações estas estabelecidas com grande contato físico, frequentes falas dirigidas à criança e intensa busca do direcionamento face a face. Tais modos de cuidados e relações são descritas como particularmente presentes em famílias ocidentais de camadas médias (Keller \& Schölmerich, 1987; Rogoff, Mosier, Mistry, Schools, \& Goncu , 1990).

Esses processos interativos envolvem quem pega a criança, como a pega, a que lhe dirige a atenção, quais recursos utilizados (Amorim, 2002), em que o corpo ou a corporeidade do bebê tem papel central (Amorim \& Rossetti-Ferreira, 2008). Os adultos, particularmente a mãe, mostram-se muito atentos às mínimas reações, sendo bastante receptivos às expressões/emoções da criança, buscando minimizar reações afetivas ditas "negativas".
Nesse contexto, comportamentos de choro (emoção prenhe de significações) são discriminados se podem/devem ou não ocorrer. Se aqueles comportamentos ocorrem, são atravessados por interpretações múltiplas (o bebê está sujo; o bebê está com frio; o bebê está com fome) e um conjunto de ações decorrem delas, em função de concepções culturais do que é considerado bom ao cuidado e desenvolvimento da criança. Nas condições, o comportamento ganha significados que, dialeticamente, implicam em significados específicos em relação à criança e à sua relação com ela (e ao papel do adulto).

Considerando os pontos abordados por Smolka (2004), sobre processos de significação, verifica-se que a afetividade construída com a criança e as (re)ações frentes às significativas emoções do bebê fazem com que a criança seja simultaneamente autor/expectador do processo. Destaca-se dessa forma a experiência como sendo simultaneamente ativa e passiva, dual, recíproca. Como Coelho Jr. (2003) menciona, há uma permanente reversibilidade entre as pessoas corporificadas. Há uma simultaneidade de ser sujeito e objeto de ato sensível. $\mathrm{Na}$ história relacional (mãe-criança), então, em função das concepções sociais (o bebê deve se apegar à mãe e ter certos comportamentos para um bom desenvolvimento), das formas consideradas ideais de cuidados e relações, as experiências adquirem significados e significam.

O choro ou expressão de incômodo significam e são significados, mostrando-se mais radicalmente abertos à cultura, esta última estando pronta para ser encontrada, moldada e remoldada, em cada momento, na contínua história da experiência. A significação encontra-se, assim, não só expressa pelas palavras (apesar de atravessada por elas). O bebê com sua expressividade emocional é significado e significa, o significado derivando da correlação com pessoas/cultura, a partir da experiência corporificada no mundo.

Desse modo, nas relações, acaba por se dar a reversibilidade, o significado do incômodo/choro se desdobrando e indicando quais as relações são significativas de serem construídas (apego aos adultos, particularmente, à mãe). Também, indica qual é a posição da criança naquelas relações (centralidade, com todo um conjunto de 
mudanças na organização doméstica para seus cuidados); e, ainda, os modos de se relacionar com as pessoas ao redor (que não pode/deve chorar / sofrer). Destaca o que uma pessoa tem em relação à outra e o que da relação tem para seu eu. Esse processo mostra, então, que não é apenas um meio, um modo de (inter)(oper)ação. Como discute Smolka (2004), constitui-se enquanto um processo histórico constitutivo da subjetividade da criança.

Nesse ponto, vale frisar que a efetivação da relação mãe-bebê se dá por que, nessa família estudada, Marina é filha única. Outras formas relacionais poderiam ser descortinadas caso houvesse irmãos, por exemplo. Ou ainda, se o estudo fosse feito em famílias de outras camadas sociais, em que as concretas condições de vida circunscrevessem outras necessidades (como as econômicas). A despeito disso, entende-se que alguns dos elementos ainda seriam preservados nessas condições, já que a dependência do bebê também contribui para circunscrever certos modos de relações, nesses contextos. Porém, apesar dos modos, as interpretações sobre os processos (como o choro) podem variar, como no caso analisado do contexto como a creche.

$\mathrm{Na}$ creche, análise do comportamento de choro e a expressão de incômodo implicaram em condições, significações e desdobramentos bastante diferentes. $\mathrm{Na}$ creche, a razão adultocriança é diversa do familiar. Ao invés de razão um-a-um (ou mais de um adulto para cada criança), tem-se um grupo de crianças para um adulto. Dadas as condições gerais do trabalho, em função da estrutura, além da organização e proposta pedagógica, a expressão de incômodo tem então, nesse ambiente, sentidos particulares. O choro deve ocorrer, sendo quase necessário (quem não chora não mama!), representando a busca da criança por atenção. $\mathrm{O}$ choro significa a criança como ativa e reverbera significados na relação e na ação do outro.

Todavia, a relação educadora-criança é perpassada pela relação com a mãe, esta última sendo considerada como a figura central de cuidado e referência à criança, como discutido no tópico anterior. Os cuidados oferecidos pelas educadoras são então transitórios e complementares ao da mãe. Nesse contexto, a mãe mostra ambivalência em relação ao choro da criança: ora preocupa-se com o choro (como indicador de sofrimento não desejado), ora o deseja (como demonstração de dor da criança pelo afastamento da mãe, esta ainda figura central de apego). O choro desdobra-se então por entre pessoas e suas significações, situando a criança nesse emaranhado e drama de relações (Vigotski, 2000).

Porém, no ambiente, pela sua própria organização, o parceiro de interação mais frequente é o par de idade. Nesse sentido, estudos vêm indicando que os bebês interagem (Amorim, Anjos \& Rossetti-Ferreira, 2012). Mais do que isso, estudos de Costa (2008, 2012) evidenciam o uso pelos bebês de recursos culturalmente significativos, nas negociações com os pares de idade.

Nos casos descritos de interações das crianças, elas têm 11 meses e nenhuma ainda adquiriu a fala. No primeiro caso, na situação de significação de incômodo (pela perda do objeto), o bebê sabe a quem recorrer (choro dirigido aos adultos - mãe e educadora - o choro não sendo reação de expressividade indiferenciada). No segundo caso, a criança chora dirigida à outra, com forte expressão de desagrado.

No caso do não amparo esperado - na resolução do conflito e devolução do objeto - a significação de incômodo impele os bebês a ações variadas. No primeiro caso, a ação se dá através de dois gestos com a mão estendida, havendo somente uma variação de posição da mão (uma com a palma da mão para cima e outra para baixo). No primeiro gesto, a mão está virada para cima, significando um pedido. Importante dizer que toda a expressividade do corpo traduz isso, em que o rosto está sem marcas de irritação, indicando expectativa. Frente à não devolução do objeto, a mão se vira para baixo e se estende, o corpo se estica, o rosto demonstra irritação e todo o corpo da criança busca tomar o objeto do outro. Os gestos não são movimentos aleatórios. Eles são significativos e já trazem marcas culturalmente definidas, no diálogo mudo entre as crianças.

No segundo caso, dá-se novamente a perda de objeto disputado. A expressão de raiva é manifestada não de maneira caótica, mas direcionada a quem lhe retirou o carrinho - a outra criança. Esta última, então, estende os braços e dedos, apontando em direção a outros carros próximos. O gesto não é aqui de pedir, solicitar algo. $\mathrm{O}$ gesto aqui apreendido indica $\mathrm{o}$ já efetivado estabelecimento da atenção conjunta (Bruner, 1983; Tomasello, 2003), de 
que ambas as crianças participam, dirigindo a atenção a um terceiro objeto (ou quarto... um segundo carro). O gesto de apontar carrega o significado de dar novas possibilidades à outra criança de ter (outro) objeto desejado, denotando percepção do espaço, compreensão do desejo do outro, de sua intecionalidade, de não abrir mão do objeto adquirido e da indicação de uma saída alternativa.

No conjunto dessas relações na creche, a organização, as pessoas presentes e o modo de lidar com as crianças (incluindo significações de incômodo), pontuam cotidianamente qual é a posição da criança naquele espaço (uma dentre outras tantas). Ainda, indicam o papel a ser assumido (mais ativo) e o que se espera dela (uso de recursos comunicativos mais intensos e novos recursos para negociação inclusive com o parceiro de idade).

Nas experiências vividas, no interjogo das corporeidades presentes (mãe-educadorascrianças) vão sendo indicadas quais as pessoas com quem se relaciona (não somente os adultos, mas também outras crianças); dentre elas, quais são as relações significativas (educadora) e em que sentido são significativas (são importantes, apesar de que a relação central é com a mãe); ainda, outras relações são possíveis de serem estabelecidas (outros bebês). Vão sendo discriminados modos de se relacionar e de se comunicar, todos carregados de significação, implicando no uso de recursos alternativos que possibilitem inclusive a superação de desafios inesperados.

Finalmente, no contexto de abrigamento, a condição é diversa. A instituição de acolhimento é, usualmente, um ambiente organizado pelo trabalho de mulheres, normalmente voluntárias e sem formação em educação infantil; ainda, é contexto em que, tradicionalmente, não se tem planejamento pedagógico à prática de cuidados das crianças (Moura, 2011).

Apesar de o ambiente ser também de educação infantil coletiva, modos de relação com a família de origem são diversos da creche. Pela condição, as famílias biológicas são vistas, usualmente, pelo viés do que não são / do que não têm!!! Muitas das funcionárias, inclusive, afirmam que as mães "Não valem nada"! (Moura, 2011). Nesse sentido, há um elo da instituição com a família de origem, aquele sendo carregado de significações negativas, a despeito de que, muitas vezes, a perda da guarda do filho está relacionada a problemas de pobreza, em famílias monoparentais. Isso resulta em que, usualmente, não se dê direito à voz às famílias. A figura central de apego (mãe) é, assim, social e juridicamente afastada das relações com a criança.

As crianças são aceitas na instituição, esta representando um espaço mais estruturado para cuidar delas. $\mathrm{O}$ espaço e relações ali estabelecidas são, dessa maneira, vistos como temporários, marcados pela ruptura com a família de origem, em espera por uma família de adoção. Essa perspectiva permanece inclusive a despeito de que as políticas têm se alterado, com a meta de reinserção das crianças junto à família biológica (Moura, 2011).

Nesse contexto, o choro do bebê carregado de significações de incômodo é significado de maneiras específicas, contextuais, dialeticamente situando a posição da criança no meio e no mundo. Como discutido por Correia (2009), a direção da construção de significado depende da interação com outro social. Isto é, como discutido pela direção do abrigo e pelas profissionais que nele trabalham, o choro não pode ser atendido de maneira usual (pegar no colo, dar atenção individualizada, manter relação face a face). Normalmente, busca-se acalmar a criança de longe, falando com ela, sem pegá-la; ou fazendo com que o bebê se distraia perto das demais crianças ou em frente à televisão. Essa prática está alicerçada em justificativas que, por um lado, temem promover um cuidado de que as funcionárias não disponibilizam (pelo excesso de trabalho e precária estrutura). Por outro lado, para não criar vínculo afetivo e evitar dor da ruptura da relação, já que a expectativa é de que o bebê saia em breve da instituição. Busca-se neutralizar ao máximo a afetividade entre funcionária e criança, busca materializada nas práticas de cuidados, através da corporeidade da criança.

A análise do processo de significação de incômodo através do choro, nesse contexto, permite verificar que ele implica e significa a posição da criança no ambiente (temporária, enquanto alijada do familiar), as relações significativas (idealmente potenciais, já que ali não estão as pessoas a quem a criança deva se apegar e constituir sua afetividade) e os modos de se relacionar com as pessoas ao redor (menor expressividade emocional; menor expectativa). Indica ainda se adultos são 
parceiros preferenciais ou não. No caso, desdobra-se no sentido de que os pares de idade, muitas vezes os próprios irmãos, são as figuras centrais de referência. Ainda, o contexto e os modos de relação contribuem à construção de significação quanto ao que se espera da criança e o que a criança deve esperar do adulto (baixa receptividade).

\section{Comentários finais}

Partindo-se de uma abordagem históricocultural, entende-se que, ao ser humano, o estabelecimento de vínculos é fundamental e fomentado também por manifestações emocionais; que, a partir das relações afetivas, parceiros sociais mediam, interpetam e atribuem significações junto ao bebê; e, que ao ser humano é impossível não significar. Assim, traçou-se o objetivo de investigar processos de construção de significados em bebês. Tal proposta foi conduzida considerando diferentes relações afetivas e contextos, a partir do comportamento de choro.

A partir de estudos de caso múltiplos, as relações afetivas construídas e os processos de construção de significados foram estudados a partir de três contextos (ambiente doméstico, creche e abrigo). À análise dos casos, verificouse que, apesar de aqueles comportamentos (choro) representarem manifestação inata, eles não são expressos/apreendidos/atendidos/ significados de maneira similar nos diversos contextos. A direção da construção de significado depende da interação com outro social, dos aspectos culturais e da organização do grupo.

Em função das condições - difíceis, adversas, diversas - dos papéis atribuídos aos vários interlocutores (bebê, mãe, educador, outras crianças) e da organização da rotina e prática de cuidados, a criança vai sendo posicionada no grupo e seu comportamento ganha sentidos, às vezes opostos. Os comportamentos emergem e são tecidos nas dialógicas relações, carregando significações que são expressas na/marcadas através da corporeidade da criança, e que dialeticamente (re)significam a criança e contribuem para constituí-la (Smolka, 2004).

Apreendendo e expressando-se pela emoção, a criança ativamente atribui e capta significações, em diálogos enraizados na cultura (mesmo quando entre pares). A emoção e a significação expressas e apreendidas através da corporeidade do bebê se mostra reversível, que passa a utilizar novos meios/recursos de agir, (re)conhecidos como significativos pelos parceiros e por si mesmos. Tais comportamentos atribuem significados, significam a criança e possibilitam que ela própria em idade precoce possa construir significações sobre ser, estar e se relacionar no mundo. A emoção (choro) - significando e sendo significada, em cada um dos diferentes contextos - constitui subjetividades, relações e afetividade com características diversas.

Entende-se que se partiu de estudos de caso e que outros estudos (em função das condições analisadas) poderiam se desdobrar através de algumas outras questões. Entretanto, também se entende que os casos não representam situações particulares somente, já que ele se caracteriza como um recorte da realidade que abrange aspectos condizentes com o contexto mais amplo. Como Von Simson (Apresentação verbal, 2009) afirma (ao tratar de memória), o individual contém conteúdos do grupo social, elementos que circulam no imaginário e prática social. Assim, é possível, com cuidado, que se vá além do próprio caso. $\mathrm{E}$, embora não se possa generalizar estatisticamente as conclusões, abre-se a possibilidade de elaborar inferências, já que o individual está atravessado pelo cultural e social, da mesma maneira como os discursos e práticas sociais são construídas pelas condutas individuais em condições relacionais.

Os casos analisados não tiveram, ainda, a intenção de comparação dos cuidados nos diferentes contextos, no sentido de se apontar qual seria melhor ou ideal. A meta foi, diante da diversidade concreta e histórica de cuidados de bebês (e de processos de construção de significados), buscar apreender indícios de como se dão tais processos considerando as condições materiais em que estão imersos. Em função dos resultados, e entendendo o uso de estudos de caso como estratégia de investigação exploratória, conclui-se pela necessidade de novos estudos, ampliando amostras e condições, de modo a se conduzir aprofundamento teórico. Ainda, dada a importância dos aspectos verificados, como a ambiguidade na construção das relações afetivas com os bebês em situação de abrigo, entende-se como importante levar essas questões ao contexto de acolhimento institucional. 


\section{Referências}

Amorim, K. S. (2002). Concretizações de discursos e práticas histórico-sociais, em situações de frequência de bebês à creche. Tese de Doutorado em Saúde Mental, Universidade de São Paulo, Ribeirão Preto.

Amorim, K. S., Anjos, A. M., \& RossettiFerreira, M. C. (2012). Processos interativos de bebês em creche. Psicologia: Reflexão $e$ Crítica, 25, 378-389.

Amorim, K. S., \& Rossetti-Ferreira, M. C. (2008). Corporeidade, significação e o primeiro ano de vida. Arquivos Brasileiros de Psicologia, 60, 67-81.

Bowlby, J. (1969). Attachment and Loss. New York: Basic Books.

Brannigan, C.R., \& Humphries, D.A. (1972). Human nonverbal behavior, a means of communication. In N. G. Blurton Jones (Org.), Ethological studies of child behavior (pp. 37-64). Cambridge: Cambridge University Press.

Bruner, J. (1983). Como as crianças aprendem a falar. Lisboa: Horizontes Pedagógicos.

Bussab, V. R., Pedrosa, M. I. P., \& Carvalho, A. M. A. (2007). Encontros com o outro: empatia e intersubjetividade no primeiro ano de vida. Psicologia USP, 18(2), 99-133.

Carvalho, A. M. A. (1998). Etologia e Comportamento Social. In L. Souza, M.F.Q., Freitas, \& M.M.P. Rodrigues (Orgs.), Psicologia: reflexões (im)pertinentes (pp. 195-224). São Paulo: Casa do Psicólogo.

Carvalho, A. M. A. (2005). Em busca da natureza do vínculo: uma reflexão psicoetológica sobre grupos familiares e redes sociais. In J.C. Petrini \& V.R. Cavalcanti (Orgs.), Família, sociedade e subjetividades: uma perspectiva multidisciplinar (pp. 183-194). Petrópolis: Vozes.

Coelho Jr., N. E. (2003). Da intersubjetividade à intercorporeidade. Contribuições da filosofia fenomenológica ao estudo psicológico da alteridade. Psicologia da USP, 14(1), 185-209.
Correia, M. F. B. (2009). Indeterminação, multidimensionalidade e relevância do processo de construção de significados. Psicologia em estudo, 14(1), 251-258.

Costa, C. A. (2008). Processo de abreviação em relações de bebês com seus pares de idade. Monografia de Bacharelado em Psicologia, Universidade de São Paulo, Ribeirão Preto.

Costa, C. A. (2012). Significações em relações de bebês com seus pares de idade. Dissertação de mestrado em Psicologia, Universidade de São Paulo, Ribeirão Preto.

Ferreira, L. D. P. M. (2012). Emoção no primeiro ano de vida: manifestações $e$ processos de transformação. Qualificação de mestrado. Universidade de São Paulo, Ribeirão Preto.

Fogel, A. (1993). Developing through relationships: Origins of communication, self and culture. Hertfordshire: Harvester Wheatsheaf.

Galvão, I. (2001). Expressividade e emoção: ampliando o olhar sobre as interações sociais. Revista paulista Educação Física, supl. 4, 15-31.

Góes, M.C.R. (1991). A natureza social do desenvolvimento psicológico. Cadernos CEDES (UNICAMP), 24, 17-24.

Keller, H., \& Schölmerich, A. (1987). Infant vocalizations and parental reactions during the first 4 months of life. Developmental Psychology, 23(1), 62-67.

Lemos, C. T. G. (1986). Interacionismo e Aquisição de Linguagem. DELTA. 22, 231248.

Meltzoff, A. N., \& Brooks, R. (2007). Intersubjectivity before language: Three windows on preverbal sharing. In S. Bråten (Ed.), On being moved: From mirror neurons to empathy (pp. 149-174). Philadelphia, PA: John Benjamins.

Mendes, D. M. L. F., \& Seidl Moura, M. L. (2004). Desenvolvimento da brincadeira e linguagem em bebês de 20 meses. Psicologia: Teoria e Pesquisa, 20(3), 215222. 
Mendes, D. M. L. F., \& Seidl Moura, M. L. (2009). Expressões faciais de emoção em bebês: importância e evidências. Estudos de Psicologia, 9(2), 307-327.

Moura, G. G. (2011). Os modos de relações de bebês que vivem em um contexto de acolhimento intitucional. Qualificação de mestrado. Universidade de São Paulo, Ribeirão Preto.

Piaget, J., \& Inhelder, B. (1978). A Psicologia da criança. Rio de Janeiro: Difel.

Pinker, S. (2002). O instinto da linguagem: como a mente cria a linguagem. São Paulo: Martins Fontes.

Pino, A. (2000). O social e o cultural na obra de Vigotski. Educação e Sociedade, 71, 45-78.

Reddy, V., \& Trevarthen, C. (2004). What we learn about babies from engaging with their emotions. Zero to Three, 24(3), 9-15.

Ribeiro, F.L., \& Bussab, V.S.R. (1998). Biologicamente cultural. In L. Souza, M. F. Q. Freitas, \& M. M. P. Rodrigues (Orgs.), Psicologia: reflexões (im)pertinentes (pp. 177-203). São Paulo: Casa do psicólogo.

Rodrigues, L. A. (2011). A concretude da (trans)formação da comunicação ao longo dos seis primeiros meses de vida: um estudo de caso. Dissertação de mestrado. Universidade de São Paulo, Ribeirão Preto.

Rodríguez, C. (2006). Del ritmo al símbolo. Los signos en el nacimiento de la inteligência: Cuadernos de Educación. Barcelona: Universitat de Barcelona.

Rogoff, B., Mosier, C., Mistry, J., Schools, K., \& Goncu, A. (1990). Toddler's guided participation with their caregivers in cultural activity. In E. Forman, N. Minick, \& A. Stone, Contexts for learning sociocultural dynamics in children development. New York: Oxford.

Rossetti-Ferreira, M. C., Amorim, K. S., \& Silva, A. P. S. \& Carvalho, A. M. A. (2004). (Orgs.), Rede de Significações e o estudo do desenvolvimento humano. Porto Alegre: Artmed.

Santana, A. P., Guarinello, A. C., Berberian, A. P., \& Massi, G. (2008). O estatuto simbólico dos gestos no contexto da surdez. Psicologia em Estudo, 13(2), 297-306.
Schirmer, C. R., Fontoura, D. R., \& Nunes, M. L. (2004). Distúrbios da aquisição da linguagem e da aprendizagem. J. Pediatria, 80(2), 95103.

Smolka, A. L. B. (1995). A concepção de linguagem como instrumento: um questionamento sobre práticas discursivas e educação formal. Temas em psicologia, 2, 11-21.

Smolka, A. L. B. (2004). Sobre significação e sentido: uma contribuição à proposta da Rede de Significações. In M. C. RossettiFerreira, K. S. Amorim, A. P. S. Silva \& A. M. A. Carvalho (Orgs.), Rede de Significações e o estudo do desenvolvimento humano (pp. 35-50). Porto Alegre: Artmed.

Tomasello, M. (2003). Origens Culturais da Aquisição do Conhecimento Humano. São Paulo: Martins Fontes.

Trevarthen, C. (2005). First things first: infants make good use of the sympathetic rhythm of imitation, without reason or language. Journal of Child Psychotherapy, 31(1), 91113.

Vaitsman, J. (1994). Flexíveis e Plurais: identidade, casamento e família em circunstâncias pós-modernas (pp. 13-74). Rio de Janeiro: Rocco.

Vallotton, C. (2011). Babies open our minds to their minds: how listening to infant signs complements and extends our knowledge of infants and their development. Infant Mental Health Journal, 32(1), 115-133.

Vigotski, L. S. (2000). Manuscrito de 1929. Educação e Sociedade, 21 (71). Recuperado em 22 de outubro de 2007, de http://www.scielo.br/scielo.php?script=sci_a rttext\&pid=S0101$73302000000200002 \& \operatorname{lng}=\mathrm{en} \& \mathrm{nrm}=\mathrm{iso}$.

Vygotsky, L. S. (1991). A formação social da mente. São Paulo: Martins Fontes.

Wallon, H. (1959). O Papel do Outro na Consciência do Eu. In M.J.G. Werebe \& J. Nadel-Brulfert, Henri Wallon (pp. 158-167). São Paulo: Ática.

Wallon, H. (1979). Do ato ao pensamento. Lisboa: Moraes Editora.

Werebe, M. J. G., \& Nadel-Brulfert, J. (1986). Henri Wallon. São Paulo: Ática. 
Yin, R. (2005). Estudo de caso: planejamento e métodos. Porto Alegre: Bookman.
Recebido em 30 de Maio de 2012

Texto reformulado em 18 de Setembro de 2012

Aceite em 22 de Setembro de 2012

Publicado em 31 de Dezembro de 2012 